\title{
Internal Control Issues: Shredding Paychecks, Bank Reconciliation Problems, And Human Resource Matters
}

Jan Colbert, Columbus State University, USA

\begin{abstract}
Shortly after placing the administrative assistant (AA) on leave for excessive unreported absences and poor work, Dr. Peters, the MBA Director at a large regional university, discovered 98 pay envelopes. These were made out to former graduate students and stuffed into a drawer of the $A A$ 's desk. The pay envelopes were given to Human Resources (HR), where they were shredded. Subsequently, two more checks - for reimbursements of program expenses - were also found. The internal auditor of the University was notified. When the AA was searching for her next position within the University, the Dean of Business, who had hiring authority over the AA, gave her a positive recommendation. The AA handled all student organization funds in that position; she was subsequently suspended.

The case focuses attention on internal control issues regarding bank reconciliations and following up on outstanding checks. Also, the matter of HR shredding the pay envelopes is an issue to be considered. The human resource issues surrounding the positive recommendation that the $A A$ received is also discussed. The various matters presented in this case fit into the components of the COSO model of internal control.
\end{abstract}

Keywords: Bank Reconciliations; Outstanding Checks; Internal Control; COSO; Control Activities; Human Resources; HR

\section{LEARNING OBJECTIVES}

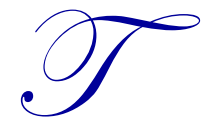

his case is intended to be utilized in graduate level courses such as those within a MBA (Masters in Business Administration), a Masters in Accountancy, or a MPA (Masters in Public Administration) program. Further, the case might be used in upper level undergraduate courses such as Auditing and Assurance Services, Enterprise Risk Management, or Internal Controls.

1. The first learning objective is to show, through a real-life example, that following up on outstanding items in the bank reconciliation is essential.

2. The second learning objective is to illustrate that handling human resource issues early may help to prevent issues in the future.

3. The third learning objective is to provide a real life example of the components of the COSO internal control model.

\section{CASE SYNOPSIS}

Dr. Peters had been recruited from among the existing faculty to be the new MBA Director at a large regional state university. The Dean of Business, who held the hiring authority, insisted that Dr. Peters retain the MBA administrative assistant (AA) when taking over as Director. Jo, the MBA AA, had well-known work issues which included coming into work late in the afternoon without calling, not completing work in a timely manner, sloppy work, and filled-to-capacity email and voicemail systems. 
Jo quickly became angry at the new more structured approach that Dr. Peters took to the MBA office and soon stopped speaking to Dr. Peters. After numerous meetings between the Human Resources (HR) Director, the Dean of Business, and Dr. Peters, Jo was placed on administrative leave and was required to go to counseling.

While Jo was on leave, Dr. Peters discovered 98 pay envelopes in Jo's desk. Two of these were for checks to former graduate assistants (GAs); 96 were pay envelopes (the monies had been direct deposited). The Dean sent the 98 pay envelopes to HR where they were shredded.

A short time later, Dr. Peters found two more checks. Fearing more shredding, he took these to the internal auditor. Dr. Peters told the internal auditor about the 98 pay envelopes and supplied a copy of the fronts of them (being an auditing professor, Dr. Peters had made copies prior to handing them over to the Dean). The latest two checks were for reimbursement.

Bank reconciliations performed in accounting had noted the outstanding payroll checks as well as the outstanding reimbursement checks. However, no one followed up on the four outstanding checks or asked questions.

The Dean went on to give the MBA AA a positive recommendation when she interviewed seeking to transfer to another position within the University. In that new area, she was in charge of the funds for all student organizations on campus. Within four years, she was suspended. If the Dean had provided factual data to the next employer on campus, perhaps that situation could have been averted.

\section{RESEARCH MEHODS}

The author was a professor and administrator at an institution of higher education during the period of time a situation similar to the one described here occurred. The identity of the parties has been changed to protect the privacy of those involved.

\section{INTRODUCTION}

When Dr. Bert Peters stepped into the role of the Director of the MBA program at a large regional university, he took over the position from an individual who became in-house counsel for the same institution. Dr. Peters had not sought out the position as MBA Director; rather, the Dean of Business had asked Dr. Peters, an auditing professor and CPA, to take the reins of the MBA program. Lacy Carter, the former Director, had been promoted to the in-house legal counsel position and had unexpectedly and quickly left the position empty.

The Administrative Assistant (AA) for the MBA program had served in that capacity during Ms. Carter's tenure in the position and for a time prior to that. Despite well-known problems with the performance of Jo Ahr for most of that period, the Dean insisted that she be retained when Dr. Peters took over leadership in the MBA program; the Dean held the budgetary control and the authority over hiring for the position.

As Dr. Peters gained knowledge and experience in his role as MBA Director, the problems with Jo Ahr the MBA AA - became more obvious. Besides not completing work and performing tasks in a sloppy manner, Jo came into work when she wanted to, often arriving sometime in the afternoon. She did this without calling and with an attitude of entitlement. Many days, she would not come in at all - again, without notifying Dr. Peters. Jo's desk was piled high with papers, her email was often at capacity, and the MBA voicemail system would often also be full. MBA students and potential students were receiving incorrect advice and reports were not being delivered or were incorrect.

During this period, both of Jo's parents were gravely ill, as they had been for several years. She chose to care for them herself in her home. Jo's three adult children and her ex-husband also lived with her; she was the only working household member. While encouraged to do so by the University's Human Resources (HR) department, Jo refused to take leave as permitted by the Family and Medical Leave Act (FMLA). 
For many years, the previous MBA Director - Ms. Carter - had permitted Jo to work flex-time. Jo had become accustomed to coming into work when she wanted to and working into the evenings. Without knowing when (or if) Jo was working, Ms. Carter approved Jo's timesheets.

The approach Dr. Peters took to the MBA office was much more structured. Dr. Peters wanted to be able to plan in advance when Jo would be in the MBA office. In order to approve Jo's timesheets, Dr. Peters wanted to know that she had actually worked. Jo immediately balked and put up great resistance, even refusing to speak to Dr. Peters. Jo's anger intensified. Many meetings took place between Dr. Peters, the Dean of the College, and the HR Director. Dr. Peters' stance was that he wanted an AA who arrived at the office on time and worked. In contrast, the HR Director repeatedly took the position that he wanted everyone in the 'family' (i.e., the University) to get along. Above all, he wanted to avoid Jo suing the University.

Eventually, at the urging of Dr. Peters, Jo was placed on administrative leave. As a condition of the administrative leave, she was required to go to counseling.

With Jo on leave, Dr. Peters faced the daunting task of sorting through the stacks of work on Jo's desk and addressing the many urgent matters at hand. The backed up phone and email messages also had to addressed.

About two months into the process of attempting to wade through the chaos of Jo's desk, and during a university holiday period, Dr. Peters discovered old pay envelopes. He counted them carefully, then recounted them and recounted them once again - 98 pay envelopes. None of the pay envelopes were made out to Jo; they were all for current or former graduate assistants (GAs). Some of the GAs had graduated and left the institution many years prior. Jo, whose duty was to have distributed these pay envelopes to the GAs, had kept them in her desk!

Dr. Peters immediately notified the Dean of the College and the Director of Human Resources by email (since the University was on holiday). He also copied the fronts of the pay envelopes. The Director of HR instructed the Dean to take possession of the 98 pay envelopes and have them sent by campus mail to HR after the break.

In a meeting a couple of weeks after the holidays with the Director of HR and the Dean regarding the administrative leave of Jo, Dr. Peters asked about the 98 pay envelopes. He learned that two of the envelopes were checks while the other 96 were pay stubs (i.e., the funds had been deposited electronically). The oldest two pay envelopes were the paychecks. Since then, the University had gone to a system of direct deposit for paychecks.

Besides learning about the two paychecks and the 96 pay stubs, Dr. Peters was appalled to find out that, upon receipt in HR, the department had had all 98 pay envelopes shredded. Further, HR had not notified accounting about the pay envelopes. Being an auditing professor and a licensed CPA, Dr. Peters was deeply concerned about the shredding; he felt that the intended recipients should have received their pay and their pay information.

About a month after the 98 pay envelopes were found and shredded, Dr. Peters found two more checks in Jo's drawers. The checks were made out to Jo and to Ms. Lacy, the former MBA Director and current in-house legal counsel.

Dr. Peters was in an ethical quandary. He was concerned that if he notified the Dean, who was his immediate boss and was also a licensed CPA, the Dean would again turn over the checks to HR. The checks would most likely again be shredded. As a CPA, Dr. Peters questioned whether that was the appropriate treatment of the checks.

The MBA Director chose to take the checks to the University internal auditor, Ida Adair. She works closely with the in-house legal counsel on investigations within the University. (That led to another issue - in-house legal counsel was Ms. Carter, the former MBA Director. Ms. Carter was the supervisor of Jo during the time of the issuance of all of the checks and could have been involved.) Also, at the time, Ms. Adair was an instructor in Business, teaching an accounting class. Still, Dr. Peters felt that that was the best option; so he went to Ms. Adair. 
Dr. Peters turned over the two reimbursement checks to Ms. Adair. He also gave her an electronic copy of the fronts of the 98 pay envelopes that had previously been located (but had been shredded by HR).

Ms. Adair was quickly able to determine that the two checks were reimbursement for expenses incurred in the MBA program. Jo had never given the reimbursement check to Ms. Lacy or cashed her own.

The internal auditor noted that a state statute requires unclaimed property be turned over to the state. Checks that are not cashed qualify as unclaimed property. Thus, the two paychecks that had been shredded and the two reimbursement checks fell under the state statute.

With the information from the copies of the fronts of the checks that Dr. Peters supplied to her, Ms. Adair was able to determine that the two paychecks were made out to graduate students who were not citizens of the U.S. Further, the two students had provided services to the University several years prior to the discovery of the paychecks stuffed in the MBA AA's drawer. However, Ms. Adair stated that the University had a duty to try to locate the two former graduate students and pay them their wages from the prior years. She indicated that if the students could not be located, the funds would be turned over to the state.

For the two reimbursement checks, Ms. Adair noted that since they had originally been issued, the University had gone to a system of direct deposit. Thus, the original checks could be voided and direct deposits could go directly into the accounts of Jo and Ms. Carter.

Ms. Adair contacted the accounting department and she was able to determine that the bank reconciliations showed the four outstanding checks.

Shortly after these events took place, the Dean permitted Jo to return from administrative leave to a position as a receptionist in the College of Business; she would never again serve as the MBA AA. In fact, while she took some classes in the building, the Dean's office directed her to never approach the MBA office. A few months later, Jo transferred, with a positive recommendation from the Dean of Business, to another position in the University. Among her duties, there is the disbursement of funds to all student organizations on campus. Four years later, the student newspaper ran a story noting that Jo had been 'suspended' pending her appeal of the suspension. No reasons for her suspension were cited.

\section{DISCUSSION QUESTIONS}

1. Who are the key actors?

2. Consider the bank reconciliations performed by the accounting department at the organization.

a. What control in the accounting department was apparently not operating that would have located both of these issues if it had been operating as designed?

b. What recommendations should the internal auditor make?

3. What control had the University already instituted between the time the reimbursement checks were first issued to Ms. Carter and Jo and the time they were discovered in the drawer that would have prevented the type of issue found in the case if it had been instituted earlier?

4. Should the matters of the 98 pay envelopes and the two reimbursement checks be included in Jo Ahr's personnel file?

5. Should HR have shredded the pay envelopes?

6. Should the internal auditor report the matter to the audit committee of the board of directors?

7. Assume that the Director of HR reports to the VP of Administration. Should the internal auditor report the matter to the Vice President of Administration?

8. Should the MBA Director have gone sooner to the internal auditor?

9. Does the MBA Director have a duty to take the issues any higher in the organization than he did?

10. Are there tax implications to the two graduate students?

11. Should the Dean have given Jo a positive recommendation?

12. Should the Director of HR have been reprimanded for having the pay envelopes shredded? 
13. Refer to COSO's Internal Control-Integrated Framework Executive Summary (2013, available at www.coso.org). Note the five components of internal control.

a. Bank reconciliations best fits into which of the five components?

b. First, HR failed to communicate to accounting regarding the existence of the old pay envelopes. Then, HR shredded the pay envelopes and did not communicate this information to anyone outside of the department. Which component of the five does this most directly relate to?

c. An internal audit function is most like to fit into which of the five components of internal control?

14. How could handling of the personnel issue with Jo potentially have saved the institution problems later?

\section{AUTHOR INFORMATION}

Dr. Jan Colbert is Professor at Columbus State University in Columbus, GA. She has published over 100 articles in a wide range of journals on topics including internal control, ethics, corporate governance, auditing standards, and sampling. In 2013, Dr. Colbert was presented with the AICPA Distinguished Achievement in Accounting Education Award. E-mail: Jan.colbert@eku.edu

\section{REFERENCES}

1. Committee of Sponsoring Organizations of the Treadway Commission. (2013, May). Internal ContolIntegrated Framework Executive Summary. Retrieved 4-1-14 from www.coso.org 


\section{TEACHING NOTES}

1. Who are the key actors?

The key actors are:

- Jo Ahrs-MBA administrative assistant

- Dr. Bert Peters-Director of MBA program and auditing professor

- Dean of Business

- Director of HR

- Lacy Carter-former Director of MBA program, in-house legal counsel

- Ida Adair--Internal Auditor

2. Consider the bank reconciliations performed by the accounting department at the organization.

a. What control in the accounting department was apparently not operating that would have located both of these issues if it had been operating as designed?

b. What recommendations should the internal auditor make?

a. Bank reconciliations are designed to locate outstanding checks. Then, the next step is that someone is to follow up on the outstanding checks. That is what did not happen in this case. Employees cash paychecks. Also, the reimbursement checks were made out to two employees; thus, the University should have expected that those checks would be cashed. All four of the checks should have been followed up on. There is no evidence that the accounting department followed up on the bank reconciliations.

b. The internal auditor should recommend that management investigate why accounting did not follow through and investigate the outstanding checks. Payroll checks should not be outstanding. Further, reimbursement checks made out to employees should not be outstanding.

3. What control had the University already instituted between the time the reimbursement checks were first issued to Ms. Carter and Jo and the time they were discovered in the drawer that would have prevented the type of issue found in the case if it had been instituted earlier?

The University had instituted direct deposit of employee paychecks and reimbursement checks. Therefore, this type of issue could not occur in the future.

4. Should the matters of the 98 pay envelopes and the two reimbursement checks be included in Jo Ahr's personnel file? HR file.

The matters regarding the 98 pay envelopes and the two reimbursement checks should be included in Jo's

As can be shown from her next position, Jo was placed in charge of funds. Then, four years later, she was 'suspended.' Having this information in her file may have helped possible employers within the institution make appropriate employment decisions. Perhaps a position in which Jo is not placed in charge of funds would be appropriate.

5. Should HR have shredded the 98 pay envelopes?

No, the pay envelopes should not have been shredded. The Director of HR, with training in human resources surely knew this. The Director of HR is responsible for the actions of the people in HR.

6. Should the internal auditor report the matter to the audit committee of the board of directors?

Because management of units are involved (the Director of HR and the Dean of Business), the internal auditor should report the matter to the audit committee of the Board of Directors. Also, the matter had been going 
on for a number of years, as the pay envelopes spanned a number of years. Further, besides the pay envelopes, there were also reimbursement checks involved. Also, the delicate matter of the involvement of the former Director of the MBA program and current in-house legal counsel makes it critical that the matter be fully vetted.

7. Assume that the Director of HR reports to the VP of Administration. Should the internal auditor report the matter to the Vice President of Administration?

Yes, the internal auditor should report the matter to the VP of Administration, since the Director of HR reports to the VP of Administration. This does not diminish the internal auditor's responsibility to report the matter to the audit committee of the Board of Directors.

8. Should the MBA Director have gone sooner to the internal auditor?

The MBA Director, Dr. Bert Peters, should have considered going to the internal auditor when he discovered the pay envelopes had been shredded.

9. Does the MBA Director have a duty to take the issues any higher in the organization than he did?

The MBA Director does not have a duty to take the issue any higher in the organization than the internal auditor.

10. Are there tax implications to the two graduate students?

The two graduate students would have paid taxes on the earnings in the year in which they earned the money. Thus, assuming they ever receive the funds, they would not again pay income taxes on the monies.

11. Should the Dean have given Jo a positive recommendation?

The Dean should have stated the facts regarding the constant condition of Jo's desk and the state of her email and voicemail systems. He should then have gone on to explain the documents (pay envelopes) stuffed in her drawer and the subsequent handling of those. Factual statements, without qualitative assessments, are sufficient for a potential employer to draw a conclusion.

12. Should the Director of HR have been reprimanded for having the pay envelopes shredded?

Yes, the Director of HR should have been reprimanded by the VP of Administration for shredding the 98 pay envelopes, including the two paychecks. Checks should go to accounting and the accounting department should handle those. The Director of HR is responsible for the actions of the personnel in HR.

13. Refer to COSO's Internal Control-Integrated Framework Executive Summary (2013, available at www.coso.org). Note the five components of internal control.

a. Bank reconciliations best fit into which of the five components?

b. First, HR failed to communicate to accounting regarding the existence of the old pay envelopes. Then, HR shredded the pay envelopes and did not communicate this information to anyone outside of the department. Which component of the five do these lack of communication issues most directly relate to?

c. An internal audit function is most like to fit into which of the five components of internal control?

a. Bank reconciliations best fit into the control activities component of internal control.

b. The HR Director failed to communicate regarding the existence of the very old pay envelopes (several years old). Then, the HR Director failed to communicate that HR had shredded the pay envelopes. These issues deal with the component of information and communication.

c. An internal audit function fits into the monitoring function of internal control. 
14. How could handling of the personnel issue with Jo potentially have saved the institution problems later?

With the Dean's positive recommendation, Jo was able to go on to a position within the University in which she handled funds. If the Dean had provided the facts of the two situations, she no doubt would not have been hired into a position in which she oversaw all of the funding for the student organizations on campus. This ultimately led to her being suspended just four years later. 